\title{
Editorial
}

\section{Photocatalysis in Environment, Energy, and Sustainability}

\author{
Wanjun Wang, ${ }^{1}$ Po Keung Wong, ${ }^{2}$ Suresh C. Pillai, ${ }^{3}$ Tian Ming, ${ }^{4}$ and Patrick S. M. Dunlop ${ }^{5}$ \\ ${ }^{1}$ Department of Chemistry and Institute of Environment, Energy and Sustainability, The Chinese University of Hong Kong, \\ Shatin, Hong Kong \\ ${ }^{2}$ School of Life Sciences, The Chinese University of Hong Kong, Shatin, Hong Kong \\ ${ }^{3}$ Centre for Precision Engineering, Materials and Manufacturing Research, Department of Environmental Science, \\ Institute of Technology Sligo, Ash Lane, Sligo, Ireland \\ ${ }^{4}$ Research Laboratory of Electronics, Department of Electrical Engineering and Computer Science, \\ Massachusetts Institute of Technology, Cambridge, MA 02139, USA \\ ${ }^{5}$ Nanotechnology and Integrated BioEngineering Centre (NIBEC), University of Ulster, Newtownabbey BT37 0QB, UK
}

Correspondence should be addressed to Wanjun Wang; wanjun@cuhk.edu.hk

Received 28 April 2016; Accepted 3 May 2016

Copyright (C) 2016 Wanjun Wang et al. This is an open access article distributed under the Creative Commons Attribution License, which permits unrestricted use, distribution, and reproduction in any medium, provided the original work is properly cited.

Photocatalysis has attracted enormous attention in solar energy conversion to provide renewable and sustainable energy source, thus solving the serious environmental and energy-related problems. Those applications include hydrogen evolution by water splitting, $\mathrm{CO}_{2}$ conversion to hydrocarbon fuels, photocatalytic pollutants degradation, and water disinfection. In the past few decades, $\mathrm{TiO}_{2}$ has been the most commonly used photocatalyst because of its low-cost, nontoxicity, and high efficiency with UV-irradiation. Meanwhile, in recent years, researchers have turned their focus to novel materials and advanced technology that may bring photocatalysis into practical use. In this regard, to move this field forward, we invited investigators to contribute original research articles on recent development of photocatalysis in environment, energy, and sustainability. This special issue consists of 9 papers, mainly related to environmental purification by using various advanced photocatalysts. A brief summary of all accepted papers is provided below.

In "Adsorption and Photocatalytic Kinetics of VisibleLight Response N-Doped $\mathrm{TiO}_{2}$ Nanocatalyst for Indoor Acetaldehyde Removal under Dark and Light Conditions," the paper investigated the removal of indoor acetaldehyde using $\mathrm{N}$-doped $\mathrm{TiO}_{2}$ photocatalyst under visible light irradiation. It was found that the mesoporous $\mathrm{N}-\mathrm{TiO}_{2}$ had a high ability to absorb acetaldehyde, which was subsequently photooxidized under visible-light irradiation. The increase in temperature would result in the decrease in the adsorption rate of indoor acetaldehyde.
The paper "Evaluation of the Antimicrobial Activity of Nanostructured Materials of Titanium Dioxide Doped with Silver and/or Copper and Their Effects in Arabidopsis thaliana" reported the sol-gel synthesis of $\mathrm{Cu}^{2+}-\mathrm{TiO}_{2}$ and $\mathrm{Ag} @ \mathrm{TiO}_{2}$ as nanostructured photocatalysts for microbial disinfection. The Ag@ $\mathrm{TiO}_{2}$ was more active than $\mathrm{Cu}^{2+}-\mathrm{TiO}_{2}$, while E. coli was more sensitive to $\mathrm{Ag@TiO}$ than S. cerevisiae. The impact of the as-prepared photocatalysts in plants was evaluated by exposing Arabidopsis thaliana Col-0 strain to these materials at different conditions and concentrations. Deleterious effects on $A$. thaliana due to exposition of silver base materials were observed at longer times of exposures and higher concentrations of photocatalysts.

The paper "Synthesis of CdS Sensitized $\mathrm{TiO}_{2}$ Photocatalysts: Methylene Blue Adsorption and Enhanced Photocatalytic Activities" reported the microwave-assisted hydrothermal synthesis of a series of $\mathrm{CdS} / \mathrm{TiO}_{2}$ nanocomposite with different $\mathrm{Cd}$ to Ti molar ratio by using $\mathrm{P} 25-\mathrm{TiO}_{2}$ nanopowder as the raw materials. Results showed that $\mathrm{CdS} / \mathrm{TiO}_{2}$ photocatalysts with low $\mathrm{Cd}$ to $\mathrm{Ti}$ molar ratios exhibited much higher activities than $\mathrm{P} 25-\mathrm{TiO}_{2}$, and the $\mathrm{CdS} / \mathrm{TiO}_{2}$ sample with $20 \% \mathrm{CdS} /(\mathrm{TCd} 2)$ showed the highest activity among all these samples, which is attributed to the low rate of electronhole recombination.

The paper " $\mathrm{TiO}_{2} /$ Halloysite Composites Codoped with Carbon and Nitrogen from Melamine and Their Enhanced Solar-Light-Driven Photocatalytic Performance" reported the fabrication of $\mathrm{C}$ and $\mathrm{N}$ codoped anatase $\mathrm{TiO}_{2}$ /amorphous 
halloysite nanotubes $\left(\mathrm{C}, \mathrm{N}-\mathrm{TiO}_{2} / \mathrm{HNTs}\right)$ using melamine as $\mathrm{C}$ and $\mathrm{N}$ source. The as-prepared $\mathrm{C}, \mathrm{N}-\mathrm{TiO}_{2} / \mathrm{HNT}$ showed higher photocatalytic activity for the degradation of methylene blue than that of $\mathrm{TiO}_{2} / \mathrm{HNTs}$.

In the paper "Synthesis of $\mathrm{CuO} / \mathrm{Co}_{3} \mathrm{O}_{4}$ Coaxial Heterostructures for Efficient and Recycling Photodegradation," a highly efficient $\mathrm{CuO} / \mathrm{Co}_{3} \mathrm{O}_{4}$ composite was synthesized on $\mathrm{Cu}$ wire mesh by a simple hydrothermal method. These $\mathrm{CuO} / \mathrm{Co}_{3} \mathrm{O}_{4}$ coaxial heterostructures were easy to recycle and exhibited enhanced photocatalytic activity for the degradation of methylene blue than that of single $\mathrm{CuO}$ nanorod arrays.

The paper "Evaluation of La-Doped Mesoporous Bioactive Glass as Adsorbent and Photocatalyst for Removal of Methylene Blue from Aqueous Solution" reported a series of La-doped mesoporous bioactive glasses (BG-La) with excellent biosafety and hypotoxicity. The BG-La showed higher photocatalytic activity than undoped mesoporous bioactive glasses (BG). The MB loaded on BG-La could be easily desorbed with acid solution due to its electronegativity and mesoporous structure.

In the paper "New $\mathrm{TiO}_{2} / \mathrm{DSAT}$ Immobilization System for Photodegradation of Anionic and Cationic Dyes," a new technique to immobilize $\mathrm{TiO}_{2}$ was developed by coating $\mathrm{TiO}_{2}$ solution onto double-sided adhesive tape (DSAT) as a thin layer binder without adding any organic additives. The immobilized $\mathrm{TiO}_{2} /$ DSAT showed lower and higher photocatalytic activity for the degradation of reactive red 4 and methylene blue than that of $\mathrm{TiO}_{2}$ powders in suspension mode, respectively. The DSAT provided a very strong interaction between glass and $\mathrm{TiO}_{2}$ layers, and therefore the reusability of immobilized $\mathrm{TiO}_{2} /$ DSAT could be up to 30 cycles.

In the paper "Hydrophobic $\mathrm{ZnO}-\mathrm{TiO}_{2}$ Nanocomposite with Photocatalytic Promoting Self-Cleaning Surface," ZnO nanorod array film on quartz crystal microbalance is modified by $\beta$-CD in hydrothermal process and then decorated by $\mathrm{P} 25-\mathrm{TiO}_{2}$ after impregnating in its suspension. The asprepared films exhibited excellent hydrophobicity as well as self-cleaning property for organics under UV-irradiation.

The paper "Enhanced Photocatalytic Property of $\mathrm{Cu}$ Doped Sodium Niobate" reported the synthesis of Cu doped $\mathrm{NaNbO}_{3}$ by modified polymer complex method. Compared with pristine $\mathrm{NaNbO}_{3}$, the as-prepared $\mathrm{Cu}-\mathrm{NaNbO}_{3}$ showed enhanced photocatalytic activity for $\mathrm{H}_{2}$ evolution from methanol aqueous solution as well as degradation of rhodamine $\mathrm{B}(\mathrm{RhB})$ under visible light irradiation. The $\mathrm{Cu}$ doping was found to improve the adsorption property of $\mathrm{NaNbO}_{3}$ and accelerate the mineralization process.

\section{Acknowledgments}

We would like to express our sincere thanks to all the authors for submitting their articles to this special issue.

Wanjun Wang

Po Keung Wong

Suresh C. Pillai

Tian Ming

Patrick S. M. Dunlop 

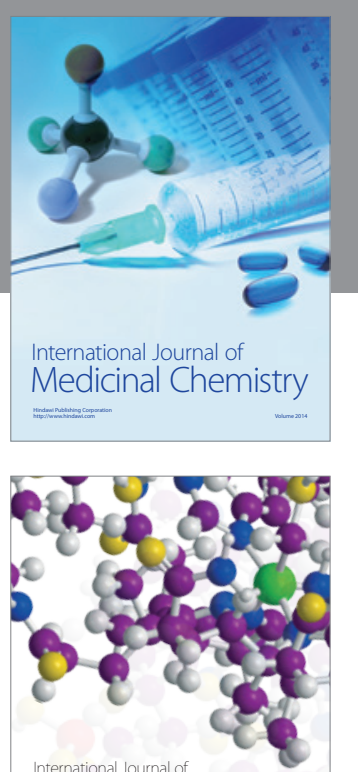

Carbohydrate Chemistry

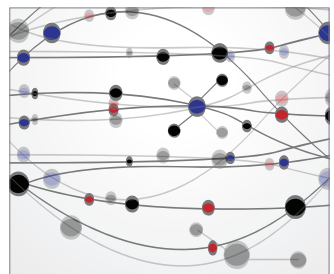

The Scientific World Journal
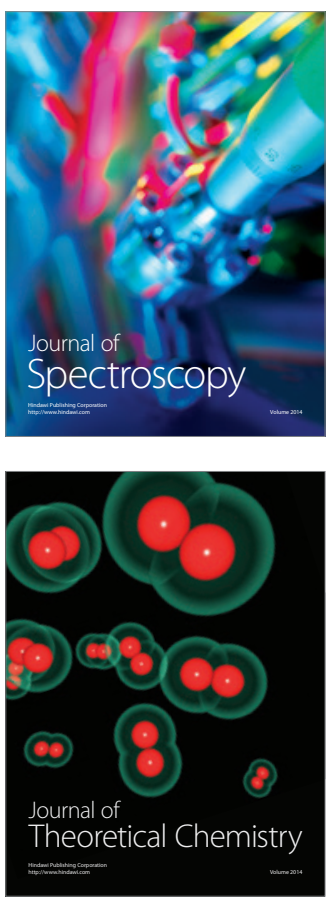
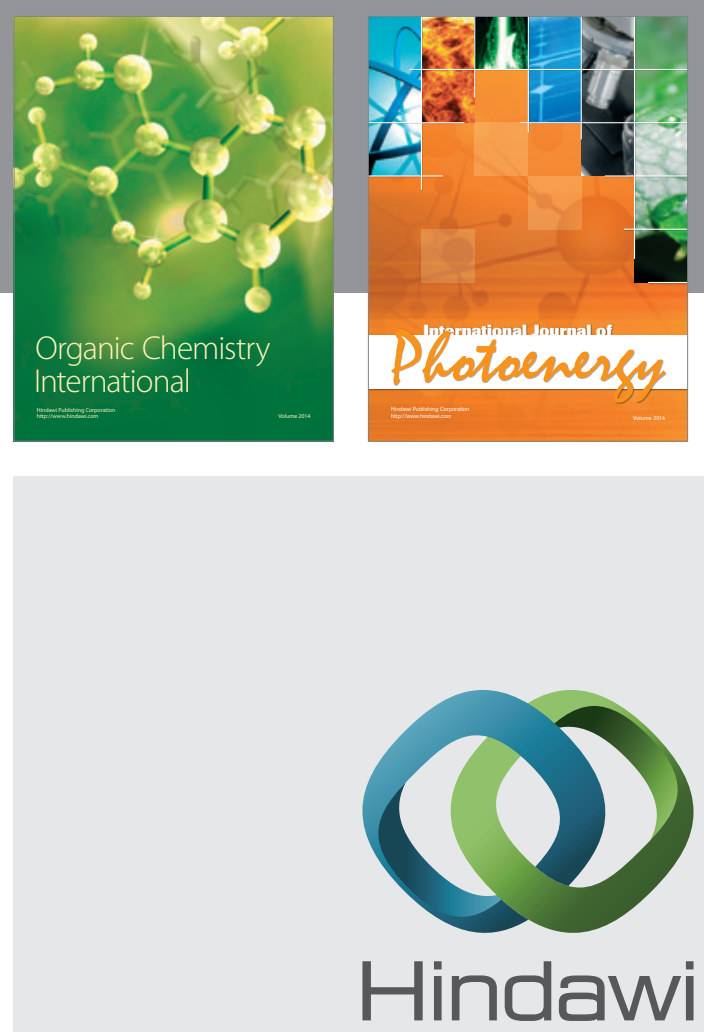

Submit your manuscripts at

http://www.hindawi.com

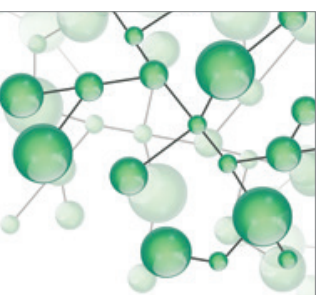

International Journal of

Inorganic Chemistry

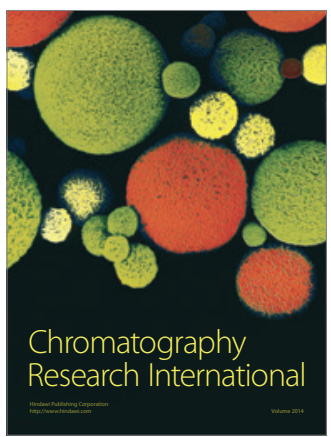

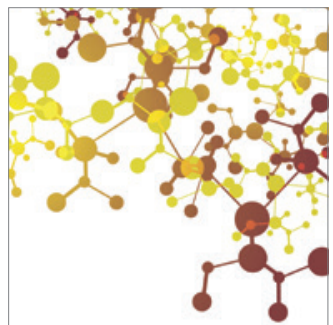

Applied Chemistry
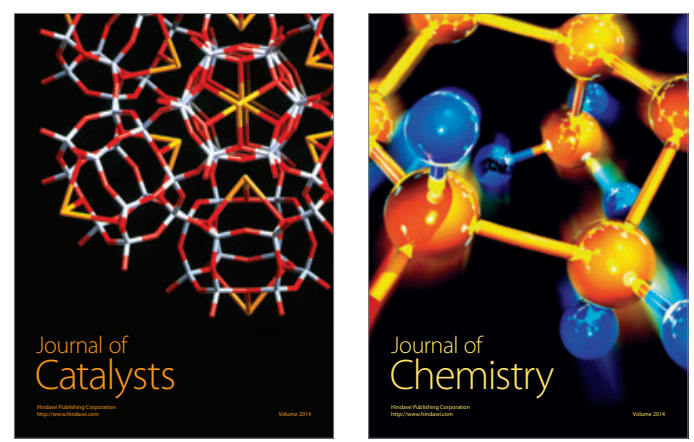
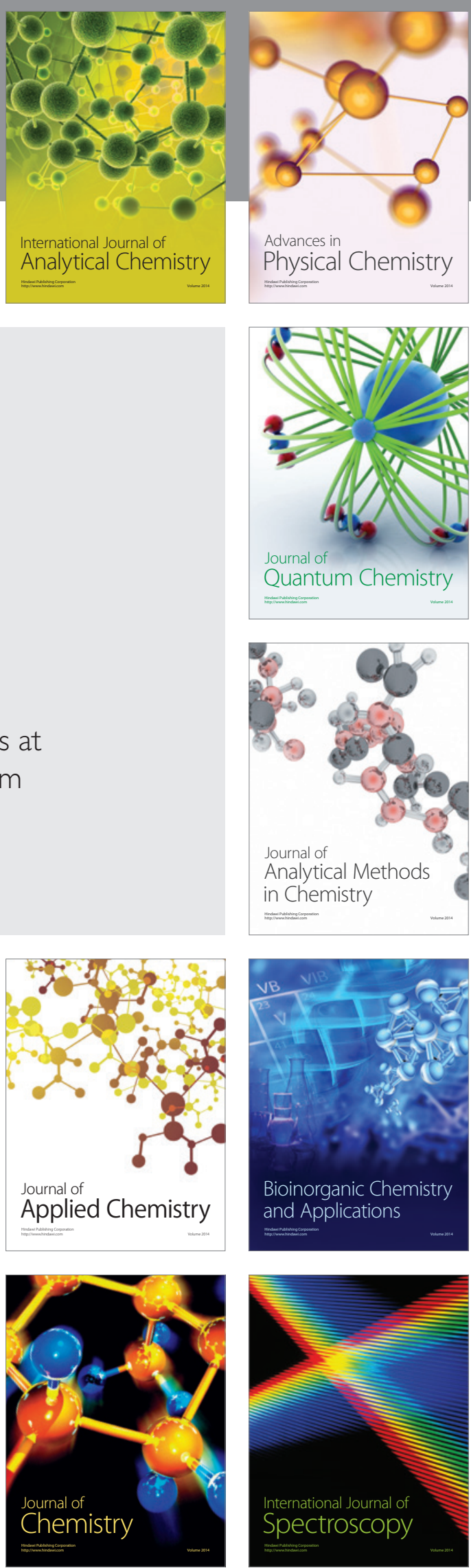